\title{
Complutum
}

ISSN: 1131-6993

\section{Metalurgia fenicia en el sureste ibérico: el taller del Cabezo Pequeño del Estaño (Guardamar, Alicante)}

Fernando Prados Martínez'; Antonio García Menárguez²; Helena Jiménez Vialás ${ }^{3}$

Recibido 23 de abril de 2017 / Aceptado: 15 de noviembre de 2018.

Resumen. Resultado del proyecto de investigación que se desarrolla desde 2014 en el Cabezo Pequeño del Estaño, se presenta el hallazgo de un edificio de planta circular, con una arquitectura excepcional, que ocupó un espacio destacado dentro del entramado urbano del poblado fenicio. El mobiliario y los objetos localizados en la excavación arqueológica han permitido reconstruir su funcionalidad, concretamente la metalurgia de la plata. La constatación de esta actividad pone de manifiesto el prestigio tanto del edificio en sí, como de los artesanos que lo emplearon a lo largo del s. VII a.C. Palabras clave: Alicante; río Segura; fenicios; taller metalúrgico; plata; siglo VII a.C.

[en] Phoenician metallurgy in the Iberian southeast: the Cabezo Pequeño del Estaño workshop (Guardamar, Alicante)

\begin{abstract}
The results of the scientific project developed in the Phoenician settlement of Cabezo Pequeño del Estaño from 2014 onwards are offered in this paper. The main finding is a circular building with exceptional furniture and architectural features occupying a prominent spot within the urban framework. The furniture and objects brought to light by excavations have allowed knowing its function: silver metallurgy. The relevance of this activity underlines the prestige of the workshop itself and the artisans who worked on it along the $7^{\text {th }}$ century B.C.

Keywords: Alicante; Segura River; Phoenicians; metallurgy workshop; silver; $7^{\text {th }}$ century BC.

Sumario: 1. Introducción. Un poblado fortificado para un primer episodio colonial. 2. La segunda fase del poblado. Una nueva generación de artesanos. 3. Metalúrgicos en la periferia de la ciudad. 4. El taller metalúrgico. Arquitectura y elementos constructivos. 5. El registro material. Mobiliario y elementos del taller. 6. Conclusiones. Un nuevo hito para el estudio de la metalurgia fenicia. Bibliografía
\end{abstract}

Cómo citar: Martínez Fernández, P.; García Menárguez, A.; Jiménez Vialás, H. (2018): Metalurgia fenicia en el sureste ibérico: el taller del Cabezo Pequeño del Estaño (Guardamar, Alicante) Complutum, 29(1): 79-94.

\section{Introducción. Un poblado fortificado para un primer episodio colonial}

Las recientes investigaciones arqueológicas efectuadas en el Cabezo Pequeño del Estaño ${ }^{1}$ de Guardamar del Segura (que abreviaremos como CPE) han permitido rescatar para los estudios fenicios este interesante yacimiento. A pesar de su conservación parcial, debido a que en 1988 padeció la acción destructora de una cantera ilegal de extracción de áridos, se trata de un asentamiento que aún está en condiciones de ofrecer informaciones de enorme relevancia sobre el primer impacto fenicio en el levante peninsular, que a tenor de los datos, pudo tener lugar desde las primeras décadas del s. VIII a.C. Ya hemos tenido ocasión de avanzar distintos aspectos sobre sus fases iniciales (García Menárguez y Prados Martínez 2014) así como sobre su fortificación, de evidente factura oriental (García Menárguez et al. 2017); pero ahora nos ocuparemos de uno de los hallazgos más relevantes: el taller metalúrgico descubierto durante las excavaciones arqueológicas llevadas a cabo entre 2015 y 2017.

\footnotetext{
Instituto de Arqueología y Patrimonio Histórico. Universidad de Alicante. 03690 San Vicente del Raspeig, Alicante, España. Correo e.: fernando.prados@ua.es

2 Museo Arqueológico de Guardamar del Segura. Calle de Colón s/n, 03140 Guardamar del Segura, Alicante, España. Correo e.: agarciamenarguez@gmail.com

3 Departamento de Prehistoria, Arqueología, Historia Antigua, Historia Medieval y Ciencias y Técnicas Historiográficas. Facultad de Letras. Universidad de Murcia. 30071 Campus de la Merced, Murcia, España.

Correo e.: vialas@um.es
} 
El CPE se sitúa sobre una elevación natural a unos $25 \mathrm{~m}$ s.n.m. en la margen derecha del río Segura, a $2 \mathrm{~km}$ de la desembocadura actual (Fig. 1), pero en un ámbito costero en el momento de su fundación (Ferrer García 2010; Tent-Manclús 2013). Hoy sabemos que su ocupación arrancó en la primera mitad del siglo VIII a.C.; de ello dan muestra las dataciones de $\mathrm{C} 14$ obtenidas en los primeros niveles de ocupación de la casamata 1 tomadas sobre semillas (CNA2734) y las fechas convencionales resultado del estudio de las cerámicas de barniz rojo y las ánforas. La loma alargada sobre la que se desplegó este enclave fuertemente fortificado aparece hoy cercenada en su lado norte por la cantera, si bien originalmente superó con creces la hectárea de superficie. Pese a ello, en la parte más alta ubicada en el sector meridional, precisamente donde la muralla alcanza alzados superiores a los $2,5 \mathrm{~m}$, se ha podido excavar una manzana de viviendas, con una casa tripartita, y un almacén que presenta dos habitaciones alargadas. Se trata de una estructura de raigambre fenicia, con paralelos en los asentamientos malagueños de Chorreras, Morro de Mezquitilla y Toscanos (Schubart 2006; Arnold y Marzoli 2009). Cabe señalar que en su excavación han aparecido restos de ánforas fenicias del tipo T. 10.1.1.1 producidas en alfares de la costa de Málaga.

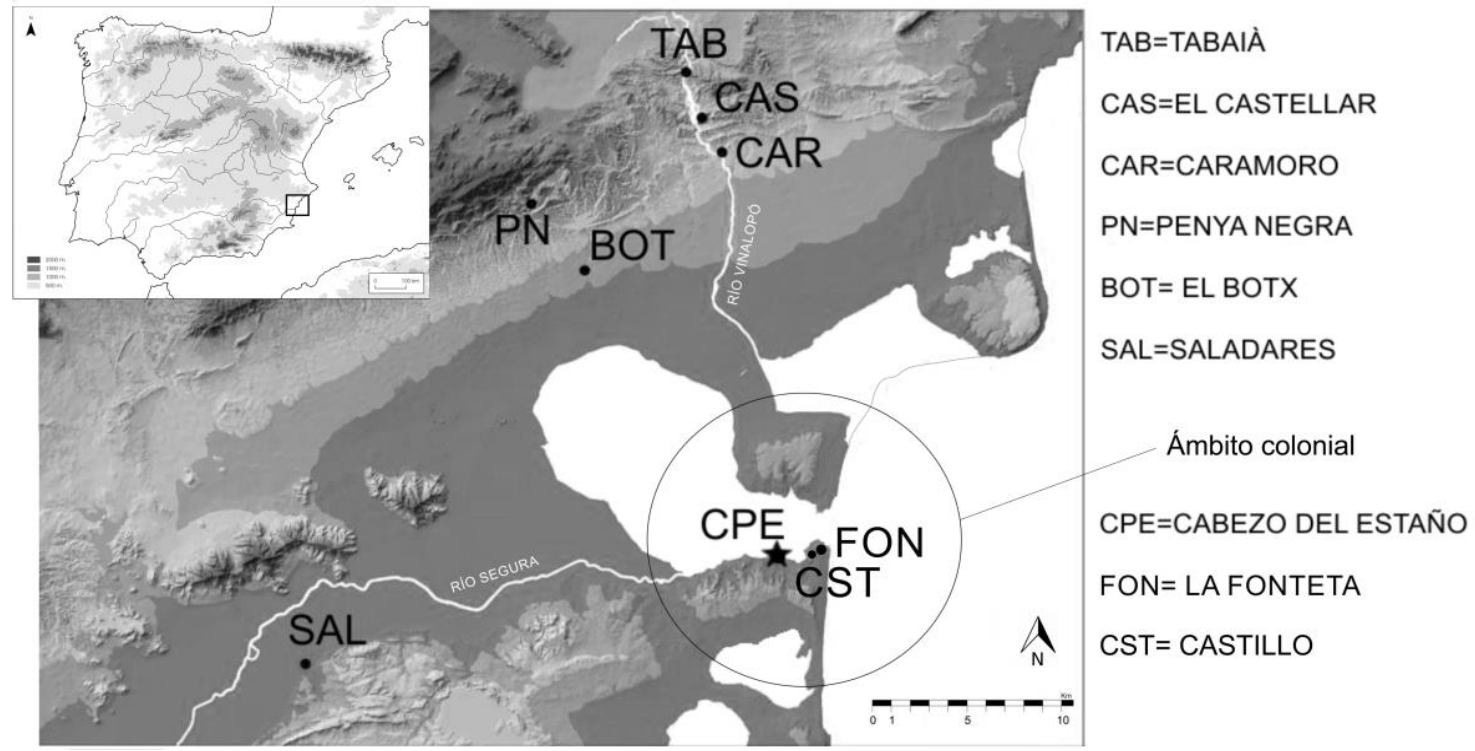

Figura 1. Mapa de la desembocadura del río Segura con indicación de los enclaves fenicios (costa) e indígenas (sierra) en el s. VIII a.C.

Las excavaciones, inicialmente concentradas en las defensas, han podido documentar dos claros momentos constructivos: el inicial, que se puede fechar en la primera mitad del siglo VIII a.C., y el segundo, que estaría marcado por un episodio sísmico que tuvo lugar hacia el tercer cuarto de la misma centuria. Del primer momento sobresale el patrón arquitectónico oriental caracterizado por la muralla de casamatas y su métrica, inédita en el occidente Mediterráneo hasta entonces (Fig. 2). Del segundo momento destaca las consecuencias del seísmo, no superior a una intensidad VI-VIII según criterios del ESI07 (GTEEM 2014), pero multiplicado en su violencia debido a la estructura calcareníti- ca del cerro (Arteaga Cardineau et al. 2016: 151). Su acción provocó múltiples destrozos así como posteriores reformas, destacando la construcción de contrafuertes y taludes para reforzar los alzados, y la adaptación de nuevos espacios apoyados sobre los escombros o cimentados sobre los derrumbes, como es el caso del taller que nos ocupa.

\section{La segunda fase del poblado. Una nueva generación de artesanos}

Nos concentraremos por tanto en este segundo momento de la vida del poblado, precisamente el que se caracteriza por presentar unos modelos 
constructivos que difieren mucho de los originales, salvo por el hecho del uso de los mismos materiales, muchas veces reempleados de la fase previa. En la arquitectura del CPE se manifiestan actuaciones frecuentes en la cultura arquitectónica fenicia: la funcionalidad y el aprovecha- miento de los materiales de construcción presentes en el entorno. Estas constantes son visibles en nuestro caso por la puesta en funcionamiento de una arquitectura antisísmica de carácter "pasivo" con taludes, tirantes y contrafuertes, que caracterizó la segunda fase del enclave.
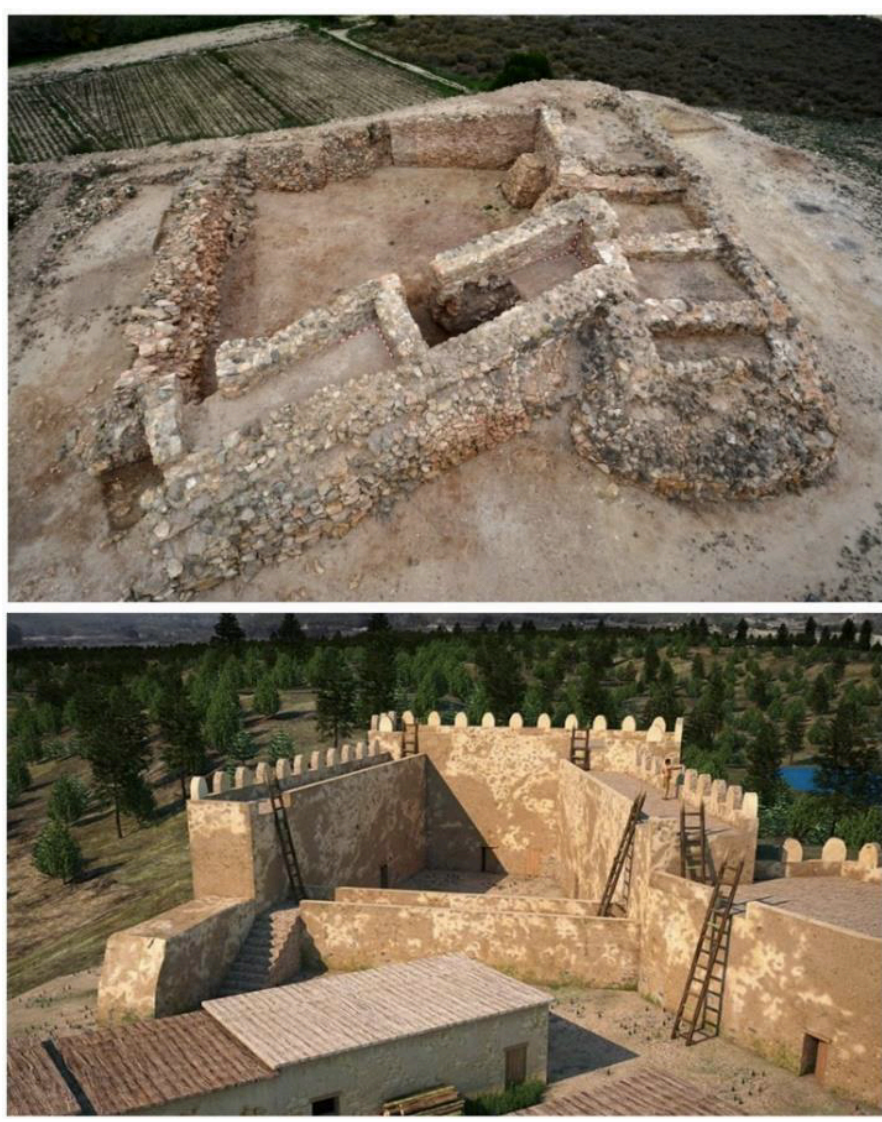

Figura 2. Vista del sector meridional del CPE o "ciudadela" y propuesta de restitución virtual

Si la fundación de este establecimiento evidencia la arribada de un grupo "ajeno" culturalmente hablando, que se estableció en una zona no habitada por comunidades indígenas como esta área marismeña, al menos durante el Bronce Final, las construcciones de la segunda fase se asocian a la siguiente generación de habitantes. Al respecto cabe señalar que no se aprecia el mismo cuidado en la factura de los paramentos, ni el uso de una metrología canónica como la que se puede apreciar en la fase inicial. Todo ello nos hacer considerar una segunda generación ya adaptada al lugar y quizá "mestiza" en cierto grado o, más sencillamente, que tras el terremoto primaron otros criterios y otras necesidades a las estrictamente representativas o defensivas del primer establecimiento. Quizás también el propio paso del tiempo supuso la normalización de las re- laciones entre indígenas y colonos. Lo que es evidente es que los taludes que se adosan a las defensas primigenias vinieron a amortizar en gran medida sus capacidades defensivas y ello hay que interpretarlo también desde un punto de vista social.

El propio patrón de asentamiento en el área marismeña del Bajo Segura, convertido por el acervo historiográfico en uno de los fósiles directores de la colonización fenicia, denota una clara distinción entre los enclaves coloniales y los indígenas, como se puede apreciar en cualquier mapa de dispersión del poblamiento de la zona. El primer impacto fenicio repercutió en el paisaje y provocó modificaciones ambientales. En el primer estadio de coexistencia, los asentamientos indígenas más cercanos, como por ejemplo Saladares o Peña Negra, sufrieron cambios demográficos y económicos 
(Arteaga Matute y Serna 1979-1980; González Prats 2010). De la misma manera, y reflejo de la iniciativa local, se detectan cambios o adaptaciones de tipo cultural o conductual, apreciables por ejemplo en los contextos funerarios (González Prats 2002: 387).

A tenor de lo comentado cabe subrayar, por tanto, que el poblamiento local (precolonial) se emplazó un paso al interior, en las laderas de las sierras que rompen el perfil de la plataforma litoral alicantina. Este patrón de asentamiento dual entre el poblamiento indígena y el fenicio es una constante en la práctica totalidad de los espacios de contacto, desde las islas centro-mediterráneas hasta el estrecho de Gibraltar. Parece que la incómoda e inestable línea costera no habría sido nunca del agrado de la población autóctona durante el Bronce Final, al contrario que para los navegantes semitas, que imitando su espacio originario en la franja libanesa, eligieron casi sistemáticamente este tipo de paisajes marismeños para establecer sus colonias, aprovechando así los recursos del mar -pesca y sal- como sucede en Sulci, Mozia, Lixus, Gadir o la propia Cartago entre otras (Aubet Semmler 1995).

Aunque es siempre complicado hacer inferencias de tipo cultural o étnico sobre los siempre complejos contextos coloniales, lo que está claro es que la segunda fase del CPE viene a demostrar una mayor integración de los dos grupos, fenicio e indígena, así como una nueva realidad arquitectónica, material y funcional.

\section{Metalúrgicos en la periferia de la ciudad}

El seísmo que se ha podido documentar en el CPE tuvo un importante efecto, a pesar de que como hemos visto no difirió en mucho de los que se suceden con frecuencia en el sur de la provincia de Alicante. Una arquitectura exógena y una mala elección del lugar de fundación del poblado -atribuible a quienes no conocían el terreno- fueron la principal causa de la destrucción. La aludida segunda fase representa, junto con un "decaimiento" en el celo constructivo, un evidente retroceso poblacional, quedando mermado el espacio habitable. La superficie útil de la zona que hoy podemos estudiar se vio claramente reducida: la práctica totalidad de las casamatas, por ejemplo, se rellenó de escombros y nunca se volvió a emplear, generando unas "cápsulas del tiempo" que a través de una cuidada disección arqueológica permiten obtener interesantes secuencias crono-estratigráficas. La calle que discurría norte-sur en paralelo a la muralla y que daba acceso a las casamatas y a las torres, se vio igualmente colmatada e inutilizada (Fig. 3). Los materiales exhumados por debajo de los derrumbes permiten situar este seísmo hacia el 740-720 a.C. (Arteaga Cardineau et al. 2016: 152).

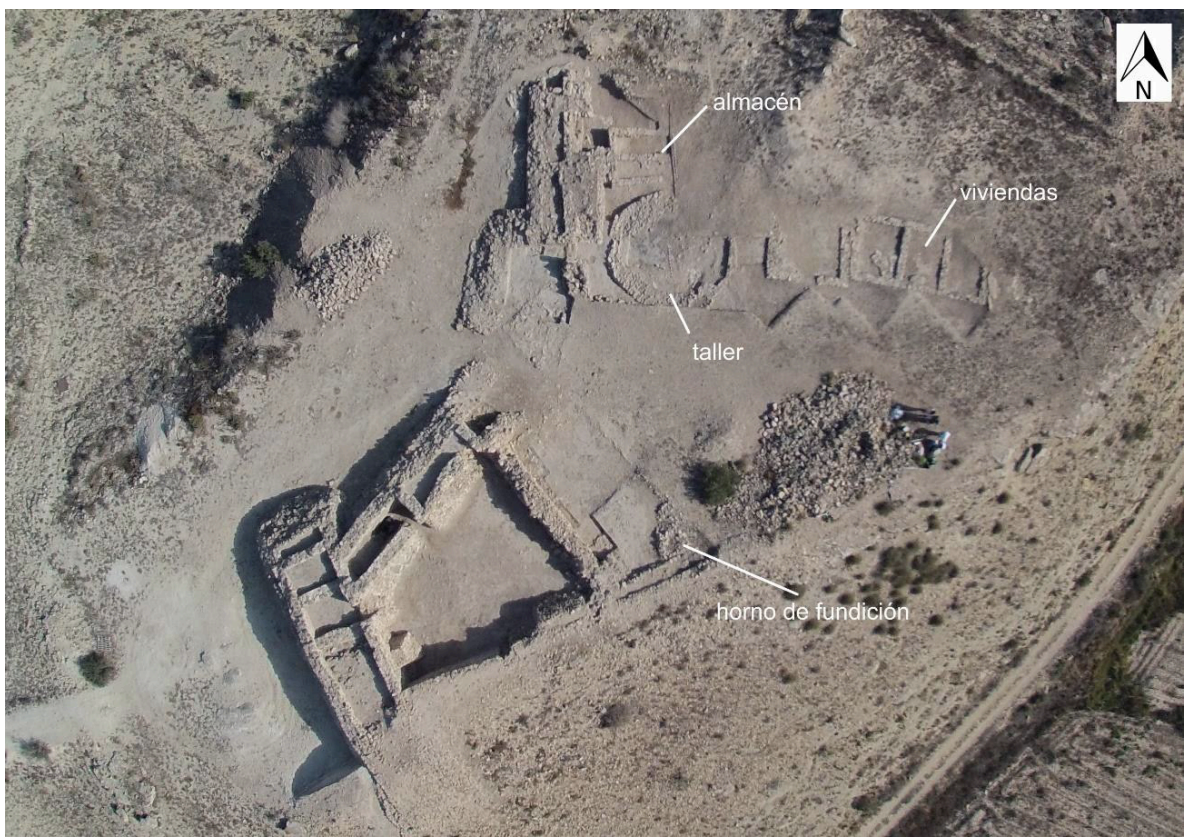

Figura 3. Vista aérea del área conservada con indicación de los elementos citados en el texto 
Pese a que parece que buena parte de la población del CPE abandonó el poblado, llevándose consigo prácticamente todo lo servible, la excavación ha permitido localizar evidencias de que un reducido grupo siguió habitando el lugar y realizando pequeñas reformas y adecuaciones de espacios y, sobre todo, desarrollando una actividad metalúrgica durante algunas décadas más. La información arqueológica con la que contamos hasta el momento viene a señalar el crecimiento y el desarrollo urbano de la vecina Fonteta justo a partir de este momento (Fases Fonteta II-III, 720-670 a.C, González Prats 2011). Es por ello que planteamos la posibilidad de que La Fonteta, de mayor tamaño (Rouillard et al. 2007) y proximidad a mar abierto, se convirtiera en el centro urbano de referencia sucediendo al viejo $\mathrm{CPE}$, que se transformaría en un hábitat secundario, especializado, enclavado dentro de su territorio. Se trataría de un proceso similar al que se ha planteado para el conjunto Rebanadilla-Cerro del Villar-Malaka en la desembocadura del Guadalhorce, un modelo polinuclear que pare- ce haber sido habitual en contextos coloniales (Delgado Hervás 2008; Sánchez Sánchez et al. 2012).

El retroceso urbano y poblacional del CPE se constata a partir de las evidencias referidas y de los niveles de abandono fechados en torno al 700-650 a.C. por las cerámicas y las dataciones radiocarbónicas en muestras obtenidas por flotación (CNA2733 y CNA2735, Fig. 4). Cabe tener en cuenta también que la presencia de diferentes asentamientos y una progresiva presión demográfica en los márgenes del área marismeña del Segura hubieron de conllevar una importante deforestación que vino a acelerar el proceso de sedimentación natural del río (hoy imperceptible debido a su sobreexplotación), en un fenómeno bien conocido en otras áreas de la costa mediterránea (Arteaga Matute et al. 1987). Esto pudo haber provocado una rápida colmatación del estuario y la inutilización del puerto que, sumado a los efectos del citado seísmo, explica a nuestro entender el abandono parcial del enclave en favor de $\mathrm{La}$ Fonteta.
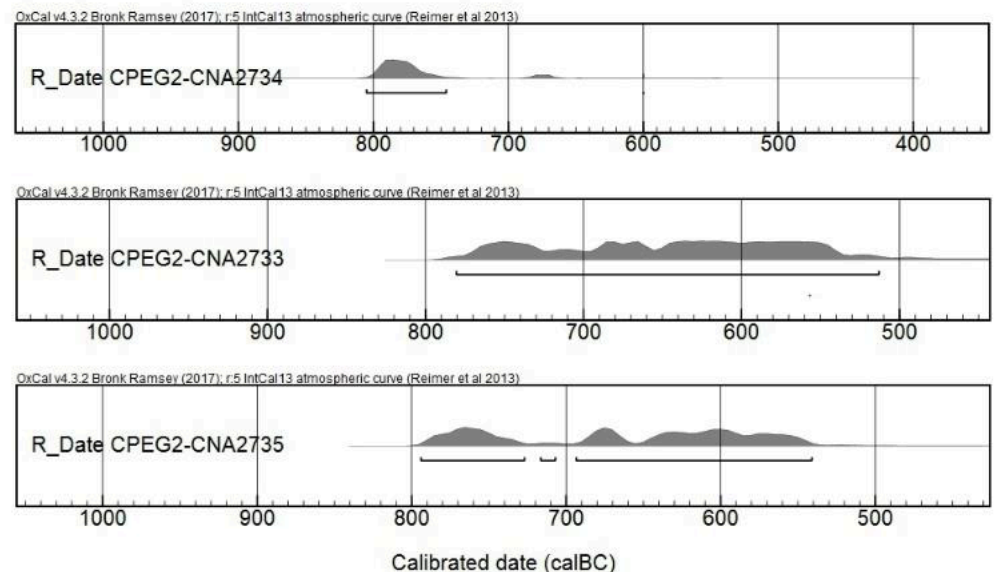

Figura 4. Gráfico bayesiano de las determinaciones radiocarbónicas calibradas (cal AC) correspondientes a la fase fundacional (CNA2734) y a la de abandono del poblado (CNA2733 y 2735)

En cualquier caso el CPE no se abandonó completamente sino que quedó integrado en el territorio de la nueva ciudad costera y plenamente instalado en las redes viarias que unían la costa con el interior a partir del eje fluvial. Esa quizás sea la principal razón, junto a la conservación de elementos construidos, para que el yacimiento siguiese ocupado durante un tiempo por un grupo más reducido, dedicado a una actividad que gracias a la excavación hemos podido verificar.
El primer aspecto interesante es que la reconstrucción y adaptación de los espacios del yacimiento tras el seísmo tuvo lugar de manera inmediata. Aunque la escasez de registro en las casas y en las zonas comunes, a excepción de los que se localizan bajo algún paramento o techumbre arrumbada, denota su abandono, en algunos puntos se observan actuaciones que tratan de paliar los efectos del seísmo, como es el caso de los contrafuertes. Las evidencias muestran que los derrumbes acontecieron en 
sentido oeste-este, y es precisamente el área oriental del yacimiento la más afectada. Las casamatas del lienzo oriental de la muralla quedaron colmatadas y los contrafuertes hoy visibles taponan los accesos rellenos de escombros procedentes del alzado.

De la zona que aún se puede estudiar, cabe señalar que al menos la casamata 1 del lienzo occidental volvió a ser utilizada, así como la torre 2. La calle que discurría en paralelo a este lienzo y que permitía acceder tanto a las casamatas como a las torres quedó, por el contrario, cubierta para siempre, con evidencias de la caída de los alzados de la muralla y las jambas de las puertas en el citado sentido. Aunque la calle quedó inutilizada, el derrumbe fue forrado con un talud y al abrigo de éste, cimentado parcialmente sobre escombros de la primera fase, se erigió la estructura del taller.

\section{El taller metalúrgico. Arquitectura y elementos constructivos}

El taller es una construcción circular de unos 4,5 m de diámetro interior (Fig. 5). Se alzó sobre un potente zócalo elaborado en mampostería de entre 1,50 y 1,60 $\mathrm{m}$ de anchura, que descansa directamente sobre la roca en el lado oriental, y sobre el derrumbe de las construcciones de la primera fase en su lado occidental. Como se aprecia en las imágenes (Figs. 5 y 6), la sólida estructura de este basamento difiere en mucho de la que presenta la llamada "vivienda metalúrgica" de Peña Negra (González Prats 1992: 245 y fig. 2), de planta oval y zócalo de doble hilera de piedras hincadas.
En nuestro caso, si bien la forma circular puede recordar a primera vista las cabañas de tradición indígena o los seguramente mal 1lamados "fondos de cabaña" (Izquierdo de Montes 1998: 286; Suárez Padilla y Márquez Romero 2014), consideramos que la envergadura de la construcción, su ubicación, su acabado interno, y de forma más contundente el repertorio material asociado, apuntan a una funcionalidad singular que adoptó dicho forma por razones exclusivamente tecnológicas.

La inusual potencia del zócalo (1,50-1,60 $\mathrm{m})$ podría a priori hacernos pensar en una torre (Fig. 6), lo que denotaría una lógica preocupación por el control y defensa de la producción metalúrgica y supondría, sin lugar a dudas, un elemento conspicuo en el paisaje. Sin embargo, el volumen de sedimento procedente de los alzados de barro excavados y el tipo de cubierta, que selló el último uso del espacio que hemos exhumado, no permite prolongar más allá de tres metros la estructura. La techumbre estuvo sustentada por dos postes de madera de los que hemos encontrado los agujeros en el pavimento. La estratigrafía es clarificadora al respecto: bajo un grueso nivel de barro de color ocre, poco compacto y estéril, se documentó un estrato de abundante ceniza y restos cocidos de barro con improntas tanto de las cañas como de los nudos que las atajaban (Fig. 7). Este nivel se documentó inmediatamente por encima del pavimento. El suelo, de barro, apareció muy compactado y cocido por acción del fuego, lo que facilitó una excavación y documentación sencilla de todos los elementos materiales que quedaron sellados tras el proceso de destrucción y abandono, ubicados bajo la techumbre caída.

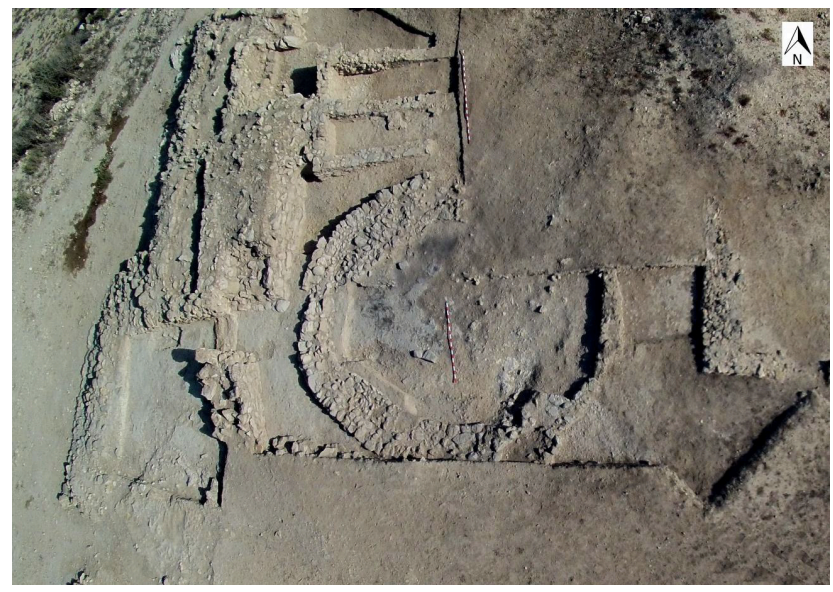

Figura 5. Vista cenital del taller. Al norte, el almacén de la primera fase y al oeste la muralla. Entre ambos, la calle colmatada por acción del seísmo 


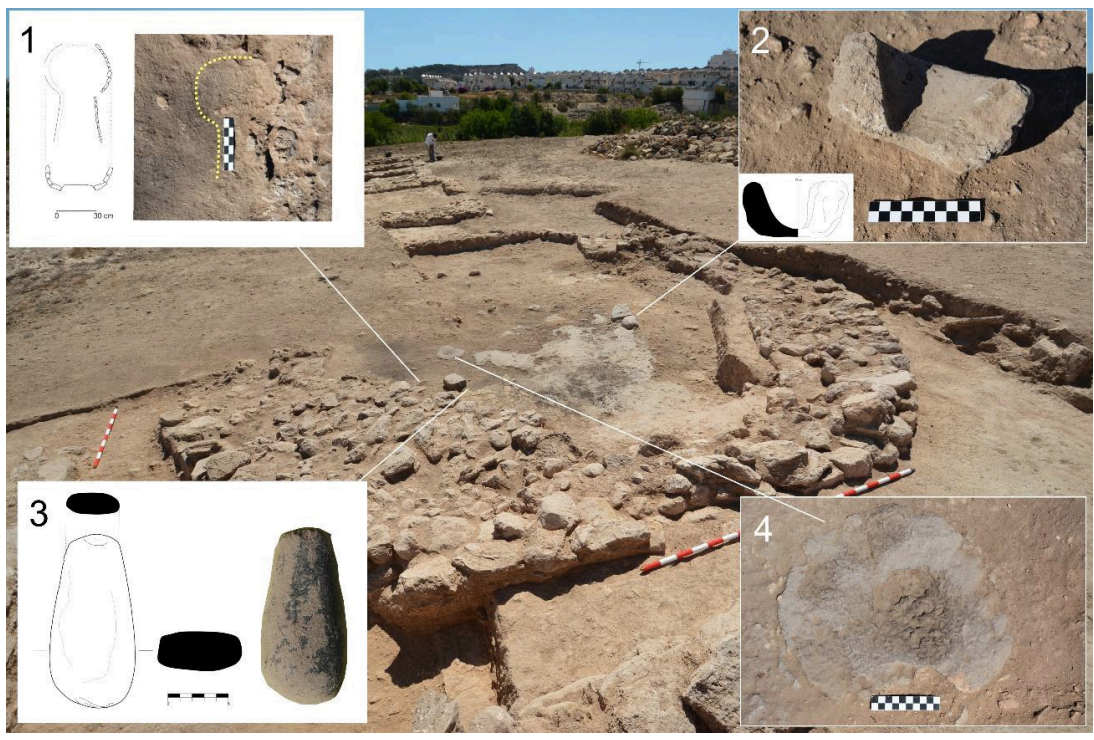

Figura 6. El taller con indicación de los ítems localizados. 1. Horno; 2. Mortero de piedra; 3. Machacador; 4. Cazoleta sobre el pavimento para verter metal derretido

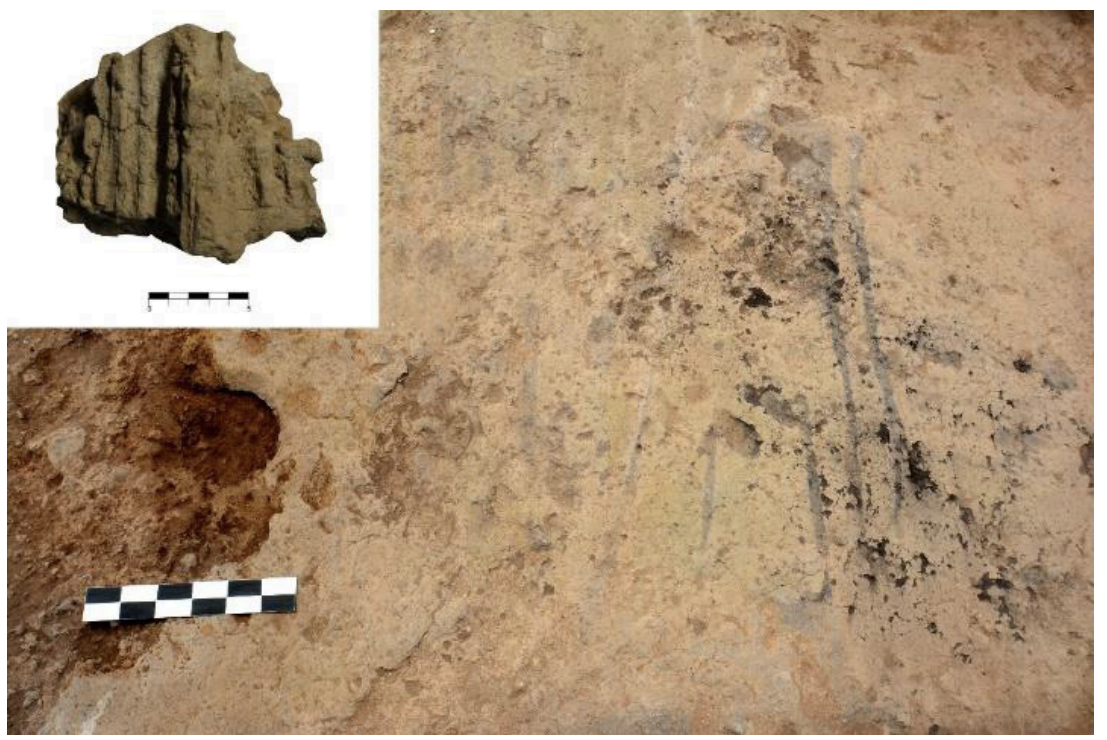

Figura 7. Sistema de cubierta del taller: pella de barro con improntas y restos de cañas quemadas sobre el suelo. Junto a la escala, el hueco de poste

La secuencia es muy clara: primero cayó la cubierta, que se incendió, quizá porque el edificio se amortizó voluntariamente tras extraer los objetos de mayor valor, y después se fue descomponiendo el alzado, de tapial, cubriendo paulatinamente los restos arrumbados y quemados de la techumbre. La secuencia evidencia un proceso de abandono del lugar, que se verá ratificada por los objetos localizados. De los materiales y del mobiliario interno nos ocuparemos en el siguiente apartado, pero ya avanzamos que su naturaleza nos es útil tanto para tratar de reconstruir la actividad que se realizó en el interior de esta estructura, como para demostrar que acaeció un abandono voluntario.

La entidad del edificio denota en todo caso que la actividad que se realizó en su interior tuvo cierta relevancia y aquéllos que la desempeñaron seguramente jugaron un papel destacado dentro del entramado social de las poblaciones del Bajo Segura en el siglo VII a.C. Recordemos en este punto la llamada "tumba del orfebre" de la vecina necrópolis de Cabe- 
zo Lucero, que, si bien se data a mediados del siglo IV a.C. por la cerámica griega del ajuar (Uroz Rodríguez 2006: 39), presenta un conjunto de matrices de orfebre con iconografía fenicia que pudo pertenecer a generaciones previas (Uroz Rodríguez 2006: 166) y que tiene paralelos en Peña Negra fechados en el siglo VII a.C. (González Prats 1983: 261). Quién sabe si estas matrices habían estado en uso durante largo tiempo, pasando de generación en generación, hasta que se amortizaron definitivamente en el momento de su inclusión en la tumba, como parte de un ajuar ibérico.

\section{El registro material. Mobiliario y elementos del taller}

Una vez descrita la estructura arquitectónica y la sencilla estratigrafía de este espacio, cabe penetrar en su interior y abordar los elementos que la caracterizan y que nos aportan la información suficiente como para plantear su función. Primeramente hemos de señalar que el espacio interno, con un área útil superior a $55 \mathrm{~m}^{2}$, era lo suficientemente grande y diáfano como para realizar determinadas prácticas de trabajo.

Aunque hemos visto que la estructura es circular en su cara externa, queremos señalar que en su interior se cuentan al menos tres bancos corridos, realizados con barro muy compacto, que dibujan un espacio hexagonal (Fig. 8). Ya hemos avanzado que la cubierta, vegetal, descansó sobre dos postes de madera, lo que de entrada permitía que el techo se elevase por igual en todo el espacio interno. En el banco ubicado en el lado norte se localizó una estructura de barro y piedras, muy compacta, a modo de mesa de trabajo, y un ánfora encastrada junto a ésta, con la boca cercenada desde el cuello (Fig. 9). Se trata de un ánfora fenicia occidental, de la que no podemos precisar su tipo al faltar el borde y las asas, pero perteneciente claramente a la familia de las T. 10 por la carena del hombro.
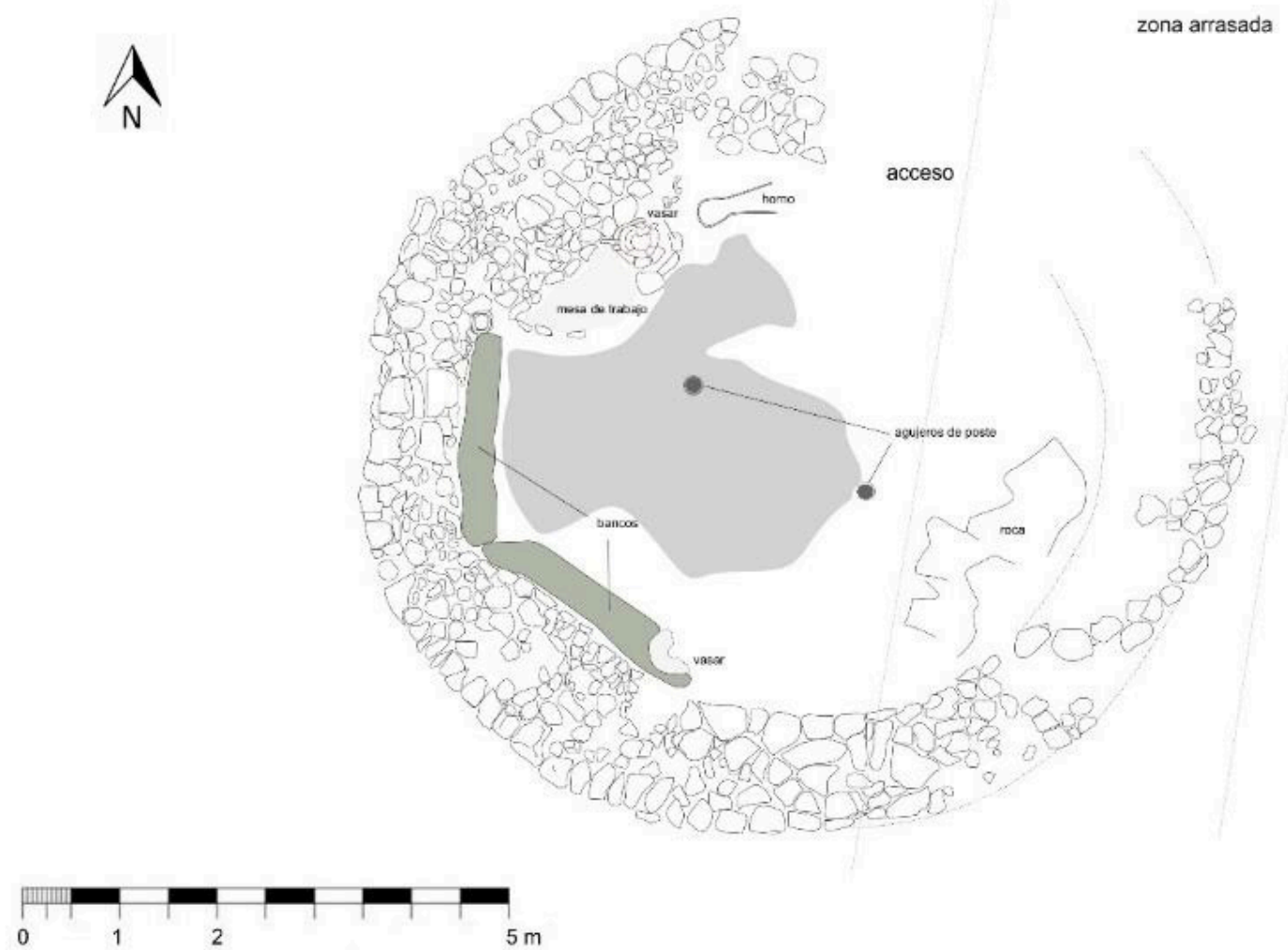

Figura 8. Planta del taller metalúrgico 


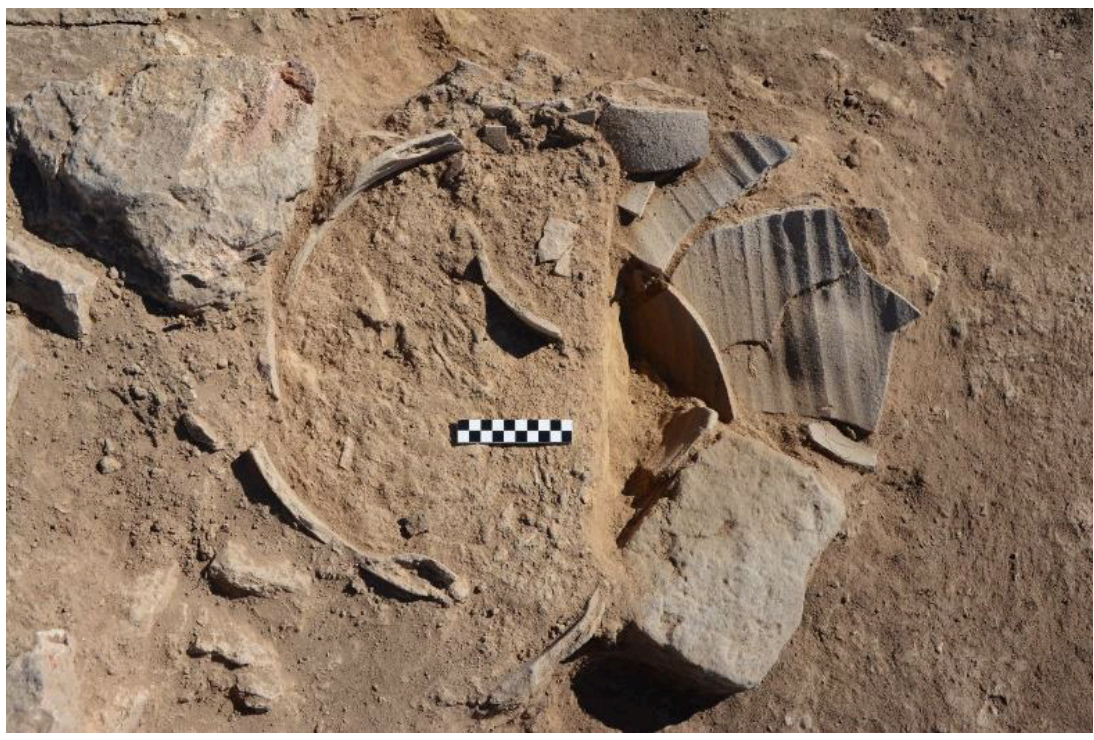

Figura 9. Vasar con ánfora cercenada por el cuello para contener agua

En el banco ubicado en el lado sur no apareció ningún objeto, aunque sí el negativo impreso en el barro de una segunda ánfora en la misma posición que la anteriormente aludida. En el banco occidental aparecieron dos vasos de cerámica a mano in situ, en concreto dos ollas abiertas, también encastradas y fijadas por la base. Bajo la techumbre y el citado nivel de incendio aparecieron numerosos elementos cerámicos correspondientes a tres pithoi de cuatro asas geminadas y a un vaso tipo "Cruz del Negro" (Fig. 10), de los que su restauración, una vez retiradas las concreciones existentes por acción del fuego, deja entrever que estaban decorados con bandas paralelas de color rojo y filetes negros. También aparecieron fragmentos de asas y pared de un ánfora fenicia. Todos estos materiales se pueden fechar sin problema hacia mediados del siglo VII a.C. (Fig. 11).

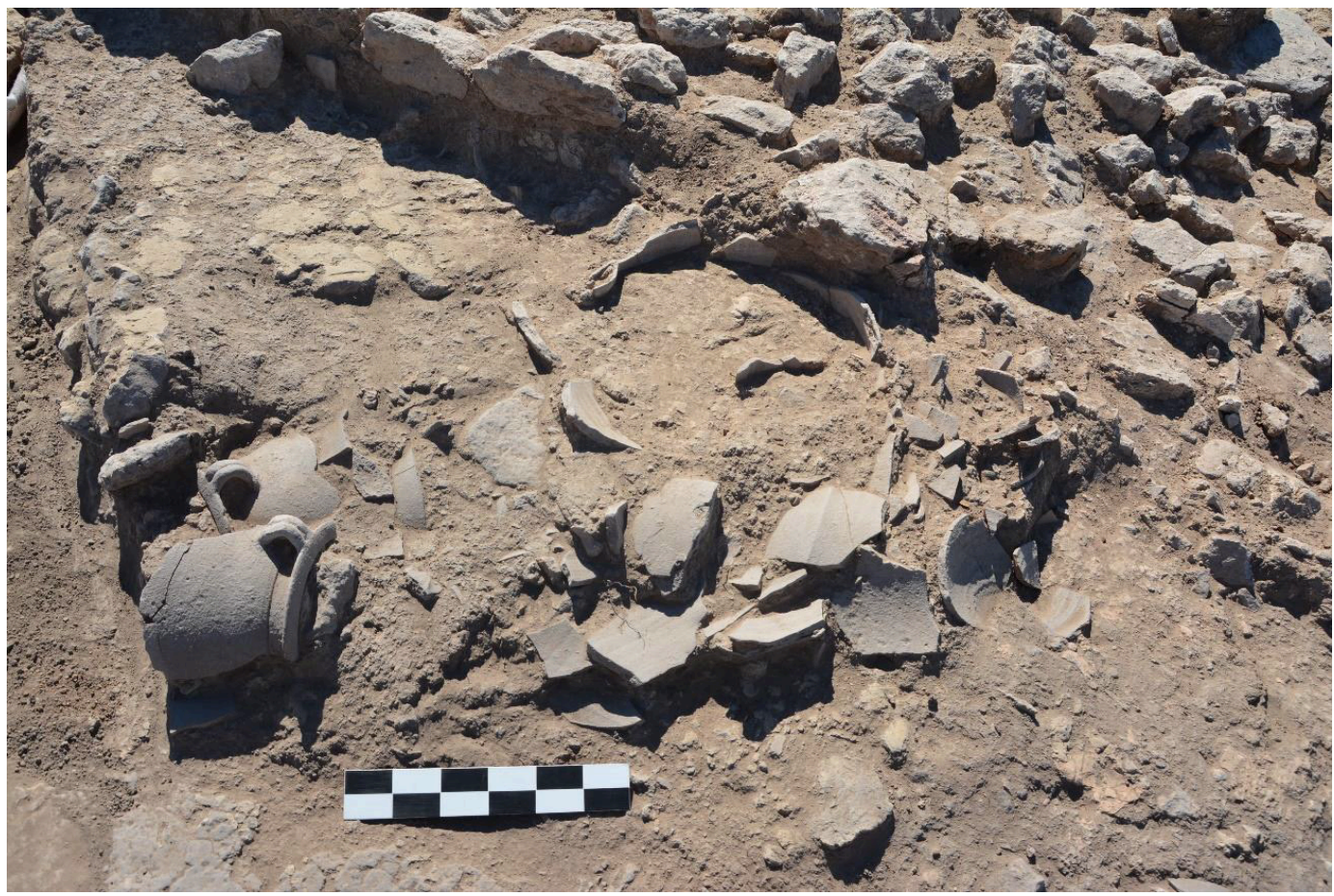

Figura 10. Banco de trabajo, vasar y restos de ánfora y pithoi fenicios 

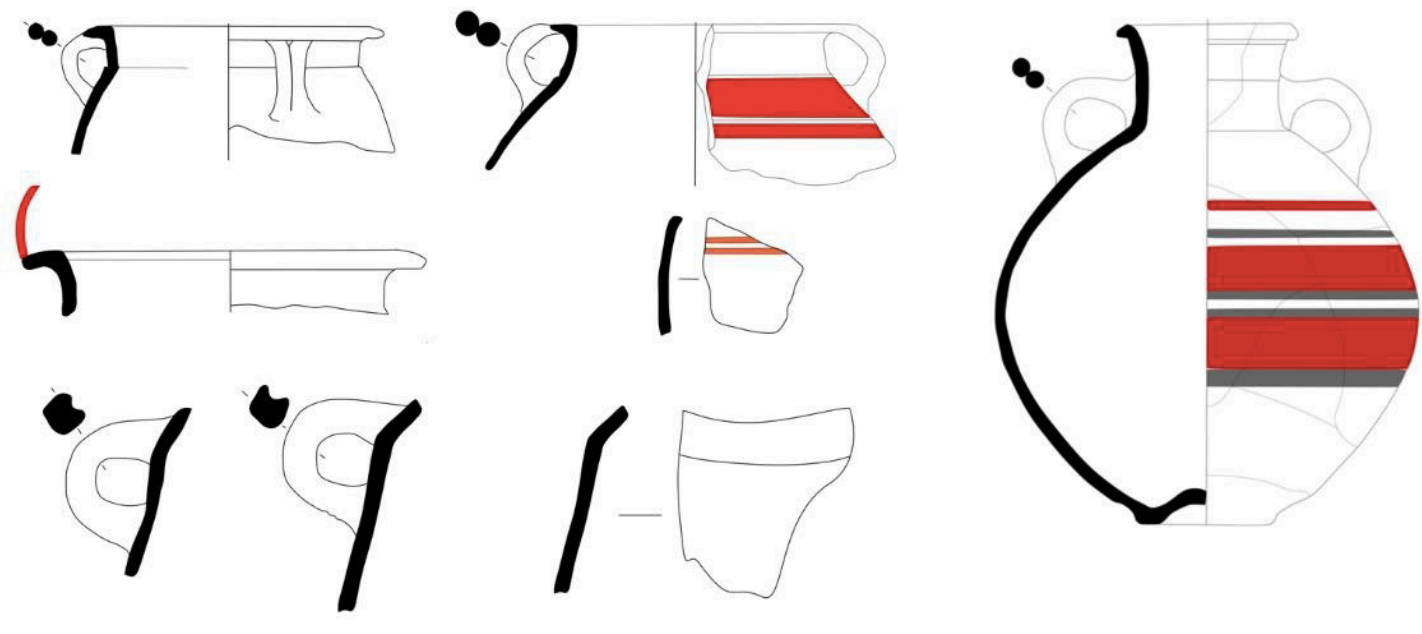

Figura 11. Selección de materiales cerámicos del taller (ánforas, pithoi y vaso tipo "Cruz del Negro”)

En las proximidades del banco ubicado al norte es donde se concentraron la mayor parte de hallazgos muebles e inmuebles (ver su ubicación en la Fig. 6). Junto a estos últimos, cabe señalar la localización de un pequeño horno con la boca abocinada (Fig. 6.1), orientada hacia la puerta del taller, que se emplazó al noreste, con una cámara de unos $30 \mathrm{~cm}$ de diámetro revestida de pequeños fragmentos de cerámica, a modo de superficie refractaria con evidencias de termoalteración. Al contrario que los hornos de fundición localizados en $\mathrm{La}$ Fonteta (González Prats y Ruiz Segura 1999; Renzi 2012) este constaba de estructura aérea y no solo de un agujero en el suelo.

Al lado del horno se hallaron unos fragmentos de una tobera prismática de perforación individual, similar a una de La Fonteta (Renzi 2007: 170) y abundante ceniza. Aunque el resto del espacio apareció vacío, en la excavación de la zona central del taller se halló la mitad de un mortero de piedra (Fig. 6.2) y un machacador de cuarcita con huellas de uso (Fig. 6.3). Por último, cabe señalar que junto al horno se localizó, sobre el pavimento, un pequeño pocito hemisférico o cazoleta con gotas de plomo en el fondo (Fig. 6.4), una pequeña torta de plomo ${ }^{2}$ y un nódulo de galena.

La concatenación de todos estos hallazgos, junto al hecho de que el horno se encontrase dentro del edificio, nos lleva a pensar que la actividad metalúrgica que se desarrolló no fue de gran envergadura pero sí de alta especialización y quizá no demasiado contaminante.
Los objetos localizados, el tamaño y el tipo de horno, junto al plomo y la galena, nos inducen a pensar en un taller de copelación de plata. Cabe señalar que el uso de la galena, abundante en las sierras del sureste, aunque no en el entorno de Guardamar (IGME 1972-1973 a y b), ya había sido documentado en los niveles fundacionales de La Fonteta (Renzi et al. 2009: 2585; Renzi 2012: 224 y ss.).

El horno, al no generar escoria, debió de fundir mineral con escasa ganga, lo que parece tener que ver con el beneficio de metales puros (Renzi y Rovira Llorens 2015: 124). Los contenedores para tener agua en abundancia a mano, y las ánforas cortadas en su tercio superior para el templado del metal fundido, son evidencias elocuentes de todo el proceso. Es cierto que no se han localizado metales, ni los moldes ni las matrices, buena muestra del alto valor de estos elementos, que quienes abandonaron el taller se llevaron consigo a un nuevo emplazamiento.

De las dos tareas principales relacionadas con la metalurgia de la plata, la fusión y la copelación, pensamos que por razones obvias la actividad que se desarrolló en el interior del taller debió de ser la segunda, aunque el mortero y el machacador evidencian que dentro se pudo realizar también el triturado inicial del mineral, por lo que esta estructura debió de estar en relación con otras en el entorno que formarían parte del mismo proceso de fabricación. En cualquier caso el pequeño horno localizado dentro del taller es muy relevante, 
pues no se conocen bien como serían este tipo de estructuras de combustión. La fusión, que separaba el régulo o lingote de la escoria, se debió de hacer en otro lugar, pues precisaba de un horno de mayor tamaño que dejaría un rastro evidente. Al respecto, entre las estructuras de la segunda fase del poblado se ha excavado una circular con abundante ceniza en el entorno, junto a piedras y pectínidos usados como fundentes.

Se trata, en definitiva, de un conjunto de elementos que alejan la funcionalidad de este espacio de una mera estructura doméstica $y$, desde luego, de una cabaña. Ya durante las antiguas excavaciones en este poblado se había aludido a una actividad metalúrgica correspon- diente con su última fase de ocupación protohistórica, propuesta que este hallazgo viene a corroborar (García Menárguez 1995). Junto a paquetes de ceniza se localizaron morteros, toberas cilíndricas con hendiduras y varios discos de barro con pequeñas perforaciones y con un hueco central (Fig. 12). El análisis realizado sobre mineral incrustado en uno de los discos señaló la existencia de aluminio y un pequeño porcentaje de plata (Fig. 13). Al norte de Guardamar, concretamente en Fontcalent, se localiza bauxita de forma natural (IGME1972-1973a) y también al sur, en el entorno de Sierra Espuña (Zarzadilla de Totana) curiosamente junto a minas de plomo (sierra de Pedro Ponce).

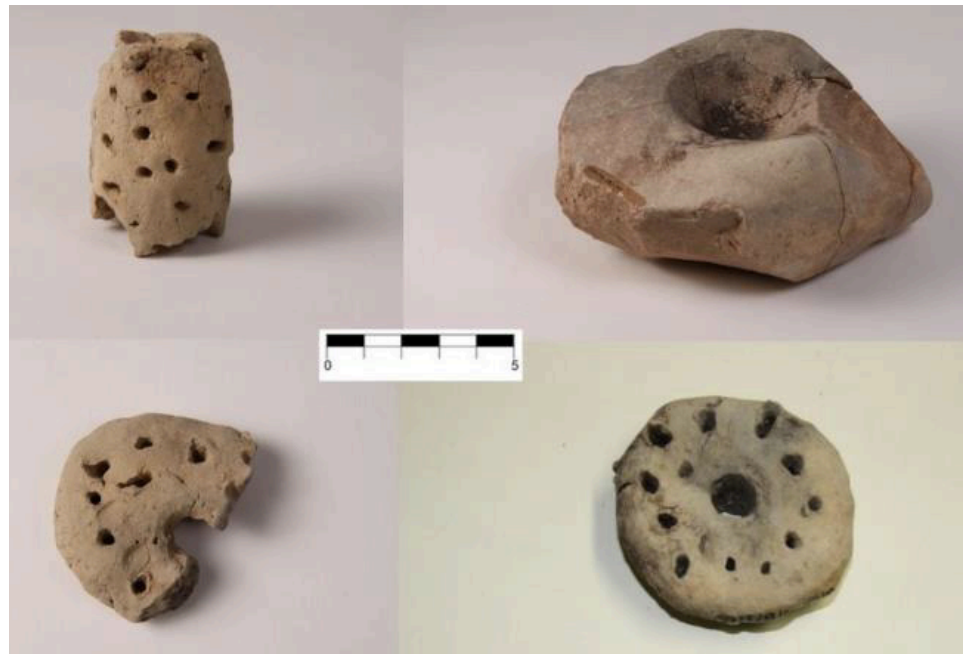

Figura 12. Instrumental metalúrgico: "coladores", discos perforados y mortero de piedra

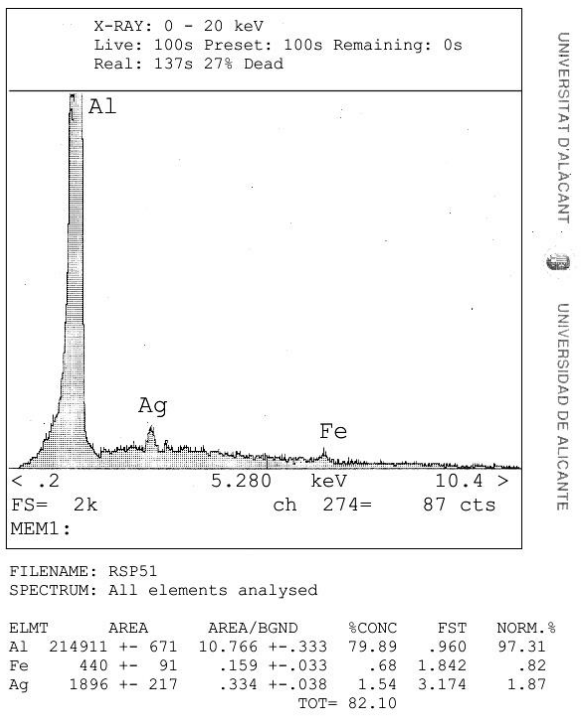

Figura 13. Composición metálica de las incrustaciones que presenta el disco perforado fragmentado 
Esta especie de "coladores" son elementos cerámicos realizados a mano y agujereados que aparecen en la práctica totalidad de los yacimientos fenicios en los que se constata copelación de plata. Bastante similares a los del CPE son otros localizados en los poblados metalúrgicos de San Bartolomé de Almonte (Huelva), Cerro de la Albina (Puebla del Río, Sevilla), Tejada la Vieja y Peñalosa (Escacena del Campo, Huelva), Campillo (Puerto de Santa María) o en los niveles arcaicos de la propia Cartago (Ruiz Mata y Fernández 1986; López Amador et al. 1996; Izquierdo de Montes 1997; Escacena Carrasco et al. 2010; Secci 2017: 538). Se trata siempre de ejemplares documentados en cronologías similares a ésta, y en ámbitos caracterizados por una fuerte interacción entre fenicios e indígenas. No está del todo clara la función de estas piezas, aunque como se ha señalado seguramente tuvieron que ver con el refinado por copelación, pudiendo ser colocados en la forja para incrementar y concentrar el calor. Sobre ellos se pudo haber emplazado la copela (Escacena Carrasco et al. 2010: 44) para calentar el lingote y propiciar la liberación del metal noble tras la oxidación del plomo.

\section{Conclusiones. Un nuevo hito para el estudio de la metalurgia fenicia}

De manera tradicional la historiografía ha querido justificar la presencia fenicia en el extremo occidente en la búsqueda de metales y la producción metalúrgica. En paralelo, las dificultades técnicas que acarrean las investigaciones sobre este tema y lo esquivo de los datos han impedido un mayor desarrollo científico. El taller que presentamos aquí pensamos que viene a sumarse al repertorio documental y a los estudios analíticos y arqueométricos que se han efectuado (Armada Pita et al. 2005; Renzi et al. 2009; Carpintero Lozano et al. 2015, entre otros).

La arquitectura del taller es, por sí misma, relevante como para poder plantear diversas hipótesis sobre su construcción, planta circular y su mobiliario interno. Pero los hallazgos, tan escasos como significativos, nos permiten reconstruir fielmente su funcionalidad. La planta circular bien podría responder a una cuestión estrictamente tecnológica y física, pues por cuestiones caloríficas y de circulación del aire este esquema es el más oportuno, y por eso se emplea generalmente para los hornos y las estructuras de combustión. Pero los bancos corridos, los contenedores de agua y las herramientas dibujan un ambiente de trabajo y no sólo un área de combustión, representada por un pequeño horno que además ocupa un espacio mínimo.

Igualmente cabe subrayar que si al exterior el taller presenta un aspecto de potente recinto circular, como elemento de prestigio bien perceptible desde la distancia, en su interior los arquitectos buscaron un espacio rectilíneo, pues como se aprecia en las imágenes los bancos corridos generan un área poligonal interna, diáfana, y se adaptan al círculo generando plataformas compactas usadas como vasares y mesas de trabajo.

La antigüedad de las cronologías que está ofreciendo el CPE en su primera fase y la complejidad de su trama urbana y su arquitectura hacen de este enclave uno de los más interesantes de la Protohistoria hispana. A ello hay que sumar ahora el taller aquí referido y la actividad metalúrgica que se ha podido constatar. Este enclave, pese a su corta duración, poco más de un siglo, y a la escasez de su cultura material, es fundamental porque se ubicó en el punto de encuentro entre culturas que supuso el área marismeña de la desembocadura del río Segura. Desde aquí, aparte de las rutas de navegación de cabotaje que recorrían el sureste con dirección al estrecho de Gibraltar a través del cabo de Gata, o la navegación hacia Ibiza, partían las rutas terrestres que jalonaban el itinerario fluvial que unía la costa con la Alta Andalucía.

La excavación arqueológica en el CPE refleja la naturaleza de los primeros contactos comerciales en esta zona: en un primer momento, reflejando relaciones complejas entre fenicios e indígenas, apreciables en otros componentes del registro como las armas (Lorrio Alvarado et al. 2016: 63). Aquí, el escenario está marcado por la necesidad de fortificar y generar espacios hábiles para almacenar excedentes en el interior del poblado, donde se han localizado, por ejemplo, evidencias de limpieza de cereal y almacenaje de grano en el interior de las casamatas. Posteriormente, y por contra, el ataludado de las murallas perdiendo valor defensivo subraya perfectamente el proceso de interacción e integración de las comunidades orientales en este territorio y el taller y las estructuras afines, quién sabe si cierta especialización en el trabajo en la periferia de los centros urbanos. Sólo el 
avance en el conocimiento a través del desarrollo de nuevas investigaciones podrá confirmar estos argumentos. En cualquier caso pensamos que este hallazgo habrá de ser fundamental en este sentido.

Aunque el registro no es muy abundante debido al referido abandono voluntario del poblado, consideramos que los elementos documentados permiten reconstruir fielmente las actividades que se llevaron a cabo desde finales del siglo VIII a.C. hasta mediados del VII a.C., en las que el trabajo de la metalurgia parece ser la ocupación principal. Por eso consideramos que este hallazgo viene a redundar en la importancia de la extracción y comercio de la galena argentífera del sureste, documentada por ejemplo en Abdera procedente de la sierra de Gádor (Carpintero Lozano et al. 2015: 9) como una alternativa a otras áreas nucleares, o quizás en el trabajo a partir del mineral argentífero del área de Mazarrón, donde se desarrolló, junto a la extracción, un proceso de obtención de plata a partir de galena argentífera en Punta de los Gavilanes (Ros Sala 1995).

Si la bibliografía más reciente determina la existencia de talleres gracias a los análisis metalográficos y químicos realizados sobre las piezas de orfebrería (Monge Soares et al. 2010), en este caso hemos podido documentar el taller en sí, aunque bien es cierto que nos faltan elementos. Somos conscientes de que el registro en lo concerniente a metal o escorias es casi inexistente, y no sabemos si por el nivel de destrucción al que se vio sometido este yacimiento alguna vez se podrán documentar los vertederos metalúrgicos, que han sido fundamentales para los estudios efectuados sobre la vecina Fonteta (Renzi 2007 y 2012). Queda igualmente pendiente la realización de los aná- lisis de los restos de escorificación adheridos a las toberas.

El CPE ofrece la posibilidad de realizar otra escala de aproximación al conocimiento de la metalurgia, que consideramos igualmente relevante: estudiar la arquitectura del taller y el ambiente de trabajo y transformación, su posición dentro del enclave y su arquitectura tipificada, distintiva y reconocible. A este respecto hemos de subrayar lo "sobredimensionado" de la misma; basta con observar las imágenes aéreas que presentamos. El taller ocupa un espacio principal dentro de la segunda fase del poblado, rompiendo el viejo esquema urbano sobre el que irrumpe, y refleja, a través de su rotundidez, la importancia de la actividad que se llevó a cabo en su interior, nada menos que la transformación metalúrgica, de la que está bien demostrada su elevada estimación social en esas fechas (Montero Ruiz y Murillo-Barroso 2016).

A excepción de los pequeños hornos de fundición de La Fonteta, en los citados ejemplos hispanos los talleres se encuentran en las cercanías de los centros mineros, y este no es el caso del CPE, donde el mineral tuvo que llegar desde lejos, al menos desde las sierras murcianas o del norte de Almería (IGME 1972-1973c). La naturaleza de la actividad que se realizó en este poblado viene a ratificar la importancia de la metalurgia en los contextos coloniales, no sólo de un primer momento sino pasado más de un siglo de convivencia e interacción de poblaciones locales y de origen semita. Quién sabe si esta noble tarea se perpetuó a lo largo del tiempo en el lugar, llegando a fundirse, literalmente, con la artesanía ibérica, pasando saberes (y quizás moldes y matrices cargadas de iconografía oriental) de generación en generación.

\section{Notas}

1. Para evitar confusión y habida cuenta de la temática de este trabajo, recordamos al lector que el "Estaño" del topónimo es la castellanización del término catalán "Estany" -laguna- (del latín stagnum). El topónimo moderno alude a la zona aún hoy inundable sobre la que se alza el cerro.

2. Muestras RSPN4: Pb 69,2\%, Ca 20,15\%, Si 6,8\%, Al 2,7\% y Fe 1,1\%. Muestra RSPN43: Pb 74,5\%, Ca 13,12\%, Si 8,7\%, Al 3,2\% y Fe 0,5\% (Lab. Servicios Técnicos de Investigación, Universidad de Alicante) 3. Esta investigación se enmarca en el Proyecto "Modular, arquitectura fenicia y púnica" que se desarrolla desde el Instituto de Arqueología y Patrimonio Histórico (INAPH) de la Universidad de Alicante y cuenta con el apoyo del Excmo. Ayuntamiento de Guardamar del Segura. Queremos expresar nuestro agradecimiento a los técnicos del Museo Arqueológico municipal (MAG). También al equipo de excavación conformado por Marco Banfo, Raquel Bujalance, Sonia Carbonell, María Celdrán, Sergio Ferrer, María Fructuoso, Livia Guillén, Marina Pons, Séfora Rueda y Octavio Torres. Por último agradecemos la colaboración de los profesores Carlos Arteaga (UAM) para el estudio arqueosismológico, José J. Martínez (UM-CEPOAT) para la fotogrametría y Guillem Pérez-Jordá (CSIC) para el análisis carpológico. 


\section{Bibliografía}

Armada Pita, X.L.; Hunt Ortiz, M.A.; Tresserras, J.J.; Montero Ruiz, I.; Rafel Fontanals, N. y Ruiz De Arbulo, J. (2005): Primeros datos arqueométricos sobre la metalurgia del poblado y necrópolis de Calvari del Molar (Priorat, Tarragona). Trabajos de Prehistoria, 62 (1): 139-155. https://doi.org/10.3989/ tp.2005.v62.i1.59

Arnold, F. y Marzoli, D. (2009): “Toscanos, Morro de Mezquitilla und Las Chorreras im 8. und 7. Jh. v. Chr. Siedlungsstruktur und Wohnhaustypologie”. (S. Helas, D. Marzoli, eds.), Phönizisches und punisches Städtewesen, Mainz: 437-460.

Arteaga Matute, O. y Serna, M. R. (1979-1980): Las primeras fases del poblado de Los Saladares (Orihuela, Alicante). Una contribución al estudio del Bronce Final en la Península Ibérica. Ampurias 41: 65-126.

Arteaga Matute, O., Hoffmann, G., Schubart, H. y Schulz, H.D. (1987): 'Investigaciones geológicas y arqueológicas sobre los cambios de la línea costera en el litoral de la Andalucía Mediterránea. Informe preliminar (1985). Anuario Arqueológico de Andalucía 1985/II: 117-122.

Arteaga Cardineau, C.; García Menárguez, A.; Prados Martínez, F. y Baudot, E. (2016): El Cabezo del Estaño de Guardamar (Alicante, España): avance preliminar de evidencias arqueosísmicas en un asentamiento fenicio del siglo VIII a.C. Mundo Investigación 2 (1): 145-155. http://mundoinvestigacion.es/ wp-content/uploads/2017/04/2-El-Cabezo-del-Esta\%C3\%B1o-de-Guardamar_ARTEAGA.pdf

Aubet Semmler, M. ${ }^{\mathrm{a}}$ E. (1995): From trading post to town in the Phoenician-punic world. (B. Cunliffe, S. Keay, eds.), Social Complexity and the Development of Towns in Iberia, British Academy, Oxford: 4765.

Carpintero Lozano, S.; López Castro, J. L. y Montero Ruiz I. (2015): Metales y metalurgia en la Abdera fenicia. Datos isotópicos sobre la procedencia e intercambio de materias primas. Archivo Español de Arqueología 88: 7-23. doi: 10.3989/aespa.088.015.001

Delgado Hervás, A. (2008): Cerro del Villar. De enclave comercial a periferia urbana: dinámicas coloniales en la bahía de Málaga entre los siglos VIII y VI a.C. (D. García, I. Moreno, F. Gracia, eds.), Contactes. Indígenes i fenicis a la Mediterrània occidental entre els segles VIII $i$ VI a.n.e., Signes, Barcelona: 6988.

Escacena Carrasco, J. L.; Feliu Ortega, M. J. y Izquierdo de Montes, R. (2010): El Cerro de La Albina y la metalurgia de la plata en Tartessos. De Re Metallica 14: 35-51. https://idus.us.es/xmlui/handle/11441/65986

Ferrer García, C. (2010): "El medio físico de la Vega Baja y el litoral de Guardamar: la génesis cultural de un paisaje”. (A. García Menárguez, ed.), Guardamar del Segura, Arqueología y Museo. Catálogo de la Exposición, MARQ, Alicante: 32-45.

García Menárguez, A. (1995): Avance sobre las excavaciones en yacimientos con fases de Hierro Antiguo en el tramo final del río Segura (Guardamar del Segura, Alicante). XII Congreso Nacional de Arqueología, Vigo: 225-229.

García Menárguez, A. y Prados Martínez, F. (2014): La presencia fenicia en la Península Ibérica: El Cabezo Pequeño del Estaño (Guardamar del Segura, Alicante). Trabajos de Prehistoria, 71 (1): 113-133. doi: $10.3989 /$ tp.2014.12127

García Menárguez, A., Prados Martínez, F. y Jiménez Vialás, H. (2017): Le mura fenicie del Cabezo Pequeño del Estaño (Guardamar del Segura, Alicante - Spagna): un esempio di "casemate walls" in Occidente. Sardinia, Corsica et Baleares Antiqvae 15: 53-65. doi 10.19272/201709701002

Garfinkel, Y. (2017): Khirbet Qeiyafa in the Sephelah: Data and Interpretations. (S. Schroer, S. Münger, eds.), Khirbet Qeiyafa in the Sephelah. Papers Presented at a Colloquium of the Swiss Society for Ancient Near Eastern Studies, University of Bern, September 6, 2014. Orbis Biblicus et Orientalis 282, Academic Press. Freiburg: 5-59.

González Prats, A. (1983): Estudio arqueológico del poblamiento antiguo de la sierra de Crevillente (Alicante), Universidad de Alicante, Alicante

González Prats, A. (1992): Una vivienda metalúrgica en la Peña Negra (Crevillente-Alicante). Aportación al conocimiento del Bronce Atlántico en la Península Ibérica. Trabajos de Prehistoria 49: 243-257. http://tp.revistas.csic.es/index.php/tp/article/view/544/562

González Prats, A. (2001): La necrópolis de cremación de Les Moreres (Crevillente, Alicante, España) s. $I X$-VII $A C$, Universidad de Alicante, Alicante 
González Prats, A. (2010): La colonia fenicia de La Fontet”. (A. García Menárguez, ed.), Guardamar del Segura, Arqueología y Museo. Catálogo de la Exposición, MARQ, Alicante: 66-79.

González Prats, A. (2011): La Fonteta. Excavaciones de 1996-2002 en la colonia fenicia de la actual desembocadura del río Segura (Guardamar del Segura, Alicante) 1, Universidad de Alicante, Alicante.

González Prats, A. y Ruiz Segura, E. (1999): Una zona metalúrgica de la primera mitad del siglo VII en la ciudad fenicia de La Fonteta (Guardamar, Alicante). XXIV Congreso Nacional de Arqueología, vol. 3, Murcia: 355-357.

GTEEM-Grupo de Trabajo Español de la Escala Macrosísmica ESI-07; Silva, P. G., y Pascua, M. A. (2014): Catálogo de los efectos geológicos de los terremotos en España, Instituto Geológico y Minero de España, Madrid.

IGME. (1972-1973a): Mapa metalogenético de España, $n^{\circ}$ 73. Alicante (E. 1:200.000).

IGME. (1972-1973b): Mapa metalogenético de España, $n^{\circ}$ 72. Elche (E. 1:200.000).

IGME. (1972-1973c): Mapa metalogenético de España, $n^{\circ}$ 79. Murcia (E. 1:200.000).

Izquierdo de Montes, R. (1997): Sobre la copelación de plata en el mundo tartésico. SPAL 6: 87-101. dx.doi. org/10.12795/spal.1997.i6.06

Izquierdo de Montes, R. (1998): La cabaña circular en el mundo tartésico. Consideraciones sobre su uso como indicador étnico. Zephyrus 51: 277-288. http://hdl.handle.net/10366/70566

Kempinski, A. y Reich, R. (1992): The Architecture of Ancient Israel. From the Prehistoric to the Persian Periods, Biblical Archaeology Society, Jerusalem.

López Amador, J. J.; Bueno Serrano, P; Ruiz Gil, J. A. y Prada Junquera, M. (1996): Tartesios y fenicios en Campillo (El Puerto de Santa María, Cádiz). Una aportación a la cronología de la Edad del Bronce en Europa Occidental, Giles, El Puerto de Santa María.

Lorrio Alvarado, A.; Pernas García, S. y Torres Ortiz, M. (2016): Puntas de flecha orientalizantes en contextos urbanos del Sureste de la Península Ibérica: Peña Negra, La Fonteta y Meca. Cuadernos de Prehistoria y Arqueología de la Universidad Autónoma de Madrid 42: 9-78. http://dx.doi.org/10.15366/ cupauam2016.42.001

Monge Soares, A. M.; Valério, P.; Silva, R. J.; Cerqueira, L. y Aráujo, M. F. (2010): Early Iron Age gold buttons from South-Western Iberian Peninsula. Identification of a gold metallurgical workshop. Trabajos de Prehistoria 67 (2): 501-510. doi: 10.3989/tp.2010.10053

Montero Ruiz, I. y Murillo-Barroso, M. (2016): Los inicios de la metalurgia y el valor social del metal. Menga: Revista de Prehistoria de Andalucía 7: 15-29.

Renzi, M. (2007): Estudio tipológico y funcional de las toberas del yacimiento de La Fonteta (Guardamar del Segura, Alicante). Trabajos de Prehistoria 64 (1): 165-177. http://tp.revistas.csic.es/index.php/tp/ article/view/100/105

Renzi, M. (2012): La Fonteta (Guardamar del Segura, Alicante) y la metalurgia fenicia de época Arcaica en la Península Ibérica. Tesis Doctoral, Universidad Complutense, Madrid. http://eprints.ucm.es/20078/

Renzi, M.; Montero Ruiz, I. y Bode, M. (2009): Non-ferrous metallurgy from the Phoenician site of La Fonteta (Alicante, Spain): a study of provenance. Journal of Archaeological Science 36 (11), November: 2584-2596. doi:10.1016/j.jas.2009.07.016

Renzi, M. y Rovira Llorens, S. (2015): Las metalurgias fenicias en el Mediterráneo. En J.M. López Ballesta (coord.): Phicaria. III Encuentros internacionales del Mediterráneo. Minería y Metalurgia en el Mediterráneo y su periferia oceánica, Universidad Popular de Mazarrón, Murcia: 114-127.

Ros Sala, M.M., (1995): Metalurgia de la plata en el yacimiento feno-púnico de Punta de Los Gavilanes (Mazarrón, Murcia). Estudio arqueológico. Actes du IIIe Congrès International des Études Phéniciennes et Puniques, Tunis, 11-16 Novembre, 1991, vol. II: 356-362.

Rouillard, P.; Gailledrat, E.; Moret, P. y Sala, F. (2007): Fouilles à la Rábita de Guardamar, II (Guardamar del Segura, Alicante). L'établissement protohistorique de La Fonteta (fin VIII Fin VI ${ }^{e}$ s. av. J.-C.), Casa de Velázquez, Madrid.

Ruiz Mata, D. y Fernández Jurado, J. (1986): El yacimiento metalúrgico de San Bartolomé de Almonte (Huelva). Huelva Arqueológica 8, Diputación Provincial, Huelva.

Sánchez Sánchez, V.; Galindo San José, L.; Juzgado Navarro, M. y Dumas Peñuelas, M. (2012): El asentamiento fenicio de La Rebanadilla a finales del siglo IX a.C. (E. García Alfonso, ed.), Diez años de Arqueología Fenicia en Málaga (2001-2010), Junta de Andalucía, Málaga: 67-85.

Schubart, H. (2006): Morro de Mezquitilla. El asentamiento fenicio-púnico en la desembocadura del río Algarrobo. Anejos de Mainake 1, Publicaciones de la UMA, Málaga. 
Secci, R. (2017): Tra Huelva e Cartagine: possibili testimonianze della coppellazione dell'argento nella Sardegna centro-orientale. (F. Prados, F. Sala, eds.), El Oriente de Occidente. Fenicios y Púnicos en el área Ibérica, Publicaciones de la Universidad de Alicante, Alicante: 537-547.

Suárez Padilla, J. y Márquez Romero, J.E. (2014): La problemática de los fondos de cabaña en el marco de la arquitectura protohistórica del sur de la Península Ibérica. Menga. Revista de Prehistoria de Andalucía 5: 199-225.

Tent-Manclús, J. E. (2013): Cambio de la línea de costa en el Bajo Segura (Sur de Alicante) en los últimos 15.000 años. Estudios Geográficos 74 (275): 683-702. doi: 10.3989/estgeogr.201324

Uroz Rodríguez, H. (2006): El programa iconográfico religioso de la 'Tumba del orfebre' de Cabezo Lucero (Guardamar del Segura, Alicante). Monografías del Museo de Arte Ibérico de El Cigarralejo 3, Murcia. 